\title{
Molecular dynamics simulation and experimental study of the surface-display of SPA protein via Lpp-OmpA system for screening of IgG
}

\author{
M. Vahed ${ }^{1,2 \dagger}$, F. Ramezani ${ }^{3 \dagger}$, V. Tafakori ${ }^{4}$, V. S. Mirbagheri ${ }^{5}$, A. Najafi ${ }^{6,7}$ and G. Ahmadian ${ }^{6 *}$
}

\begin{abstract}
Staphylococcal protein A (SpA) is a major virulence factor of Staphylococcus aureus. S. aureus is able to escape detection by the immune system by the surface display of protein A. The SpA protein is broadly used to purify immunoglobulin G (lgG) antibodies. This study investigates the fusion ability of Lpp'-OmpA (46-159) to anchor and display five replicate domains of protein A with 295 residues length (SpA295) of S. aureus on the surface of Escherichia coli to develop a novel bioadsorbent. First, the binding between Lpp'-OmpA-SPA295 and IgGFc and the three-dimensional structure was investigated using molecular dynamics simulation. Then high $\lg G$ recovery from human serum by the surface-displayed system of Lpp'-OmpA-SPA295 performed experimentally. In silico analysis was demonstrated the binding potential of SPA295 to lgG after expression on LPP-OmpA surface. Surface-engineered E. coli displaying SpA protein and lgG-binding assay with SDS-PAGE analysis exhibited high potential of the expressed complex on the E. coli surface for lgG capture from human serum which is applicable to conventional immune precipitation.
\end{abstract}

Keywords: Protein A-lgG interaction, Surface-displayed OmpA, Protein interaction, Molecular dynamics

\section{Introduction}

Staphylococcus aureus protein A (SpA) is a surface component of the bacteria (Ton-That et al. 1999) which play a role as a key virulence factor for the $S$. aureus pathogenesis. This is achieved through strong binding of the SpA to the Fcy domain of various species of IgG (Sjodahl 1977) and the Fab domain of VH3-type of B cell receptors (Cary et al. 1999). SpA is comprised of five Ig-binding domains arranged as (IgBDs) E, D, A, B, and C (Boyle 1990). Protein $\mathrm{A}$ is able to bind, with high affinity, to most IgG subclasses of human, cows, pigs, hamsters, horses, pigs, and rabbits and with low affinity to chicken, goat, rat IgG

\footnotetext{
*Correspondence: ahmadian@nigeb.ac.ir

${ }^{\dagger} \mathrm{M}$. Vahed and F. Ramezani-co-first authors

${ }^{6}$ Department of Environmental and Industrial Biotechnology, National Institute of Genetic Engineering and Biotechnology (NIGEB), P.O.BOX

14965/161, Tehran 1497716316, Iran

Full list of author information is available at the end of the article
}

subclasses (Hadji-Ghasemi et al. 2003). This protein has been widely used for quantitative and qualitative immunological techniques including different kinds of ELISA (Lofdahl et al. 1983; Tashiro and Montelione. 1995).

Display of heterologous proteins on the bacterial surface has been demonstrated as a multi-strategy approach to develop an efficient vaccine for $S$. aureus development (Kim et al. 2010; Kalyanasundram et al. 2015), screening of antibody libraries (Cavallari 2017), development of whole-cell bioadsorbents (Tafakori et al. 2012), and biosensors (Furst et al. 2017). Chimeric protein system of the Lpp'-OmpA is used as an anchor and loads heterologous proteins onto the Gram-negative bacterial surface (Yang et al. 2008a, b; Georgiou et al. 1996). Lpp'-OmpA consists of the first nine aminoacids of the E. coli lipoprotein (Lpp) which is fused to the residues 46-159 of the OmpA porin protein family to anchor bacterial cell wall envelope (Francisco et al. 1992; Tafakori et al. 2014). 
We examined the possibility of surface displaying of SpA295 via a Lpp'-OmpA system and its binding capability to $\operatorname{IgG}_{\mathrm{FC}}$ using bioinformatics and computational tools, which was confirmed by the experimental methods. SpA protein was successfully immobilized on the E. coli surface using an Lpp'-OmpA (46-159) fusion system to develop an efficient method for purification and immunoprecipitation of IgG antibodies.

\section{Materials and methods}

\section{Computer modeling}

The structure of SpA protein according to the amino acid sequence in this study that comprises five repeat domains of 295 amino acid residues in length $\left(\mathrm{SpA}_{295}\right)$ was predicted by ModWeb server (Pieper et al. 2014). The nucleotide sequence of the Lpp'-ompA-Spa construct was submitted to genebank with the accession number: MT680197. The Geometric coordinates of X-ray crystallography of IgG were obtained from RCSB protein data bank with the access code: $4 \mathrm{ZNC}$.

\section{Computational condition of docking and molecular dynamic simulation}

To provide the stable structure of Lpp'-OmpA-SPA295, this complex was subjected to molecular dynamic (MD) simulation for $30 \mathrm{~ns}$. MD simulation was performed by GROMACS 5.0.5 software (Van Der Spoe et al. 2005) and OPLSAA force field similar to that shown in the previous study (Ghahremanifard et al. 2018; Hashemzadeh et al. 2018; Fasehee et al. 2018) The molecules were placed in a dodecahedron box containing the water molecule in TIP3P model. In order to create the ionic conditions of 0.15 molar, water molecules were replaced with $\mathrm{Na}^{+}$and $\mathrm{Cl}^{-}$ions and the total charge of system was neutralized. The initial energy minimization was performed using the steepest descent algorithm. After that, the NVT simulation was performed for $50 \mathrm{ps}$ and followed by the NPT ensemble for $30 \mathrm{~ns}$. In order to maintain the temperature of $300^{\circ} \mathrm{K}$ and the pressure of $1 \mathrm{bar}$, nose-hover thermostat and Berendsen barostat were used, respectively. $\mathrm{R}=1.2$ was considered for electrostatic and van der Waals interactions.

The stable structure of Lpp'-OmpA-SPA295 from primary MD simulation was used to investifate the interaction of this structure with IgG. For this purpose, the HDOCK server (Yan et al. 2017) was employed to investigate Lpp'-OmpA-SpA295-IgG interaction according to default parameters of protein-protein free docking hybrid algorithm of template-based modeling.

The complex obtained from the HDOCK server was subjected to $30 \mathrm{~ns}$ molecular dynamic simulation under the conditions used for the primary MD simulation.

All structures visualized by the Discovery studio. The number of hydrogen bond (H-bond) formed between acceptor and donor atoms is measured using the geometrical criteria of a donor-acceptor distance less than $3.5 \AA$ by RING 2.0 web server (The RING 2.0 web server for high quality residue interaction networks).

\section{Materials used in experimental model}

List of the primer pairs, bacterial strains and plasmids used in this study are listedin Table 1 . The SpA gene were amplified from the genomic DNA of $S$. aureus (ATCC 6538) as a template, the Pfu DNA polymerase (Fermentas, Germany) and primers shown in Table 1. For design of growth curves and optimization tests, bacterial cultures were grown in Luria-Bertani (LB) medium containing $50 \mathrm{mg} / \mathrm{ml}$ kanamycin sulfate. Isopropyl ß-D-thiogalactopyranoside (IPTG) was used to induce

Table 1 Primers, plasmids and strains used in this study

\begin{tabular}{|c|c|c|}
\hline Primer, plasmid or strains & Description or genotype & Source or reference \\
\hline \multicolumn{3}{|l|}{ Primer } \\
\hline $\mathrm{PAF}-E C O R I$ & GGGG G AAT TC T GCA AAT GCTGCGCAACAC & MWG \\
\hline PAR-Xhol & GGGG CTCGAG TTTTGGTGCTTGAGCATCGT & MWG \\
\hline P1 (LPO1-F) Ndel & GGGGCATATGAAAGCTACTAAACTGGTACTGGGCAACCCGTATGTTGGCTTTGAAATGGG & Tafakori et al. (2012) \\
\hline LPOTA, ECORI & GGGGGAATTCGCTCCCGGAATGCCGTTGTCCGGACGAGTG CC & Tafakori et al. (2012) \\
\hline $\begin{array}{l}\text { PET 26b } \\
\text { PET 26b-IOAE (pLOAa) }\end{array}$ & $\begin{array}{l}\text { T7 promoter, an N-terminal pelB signal sequence for potential periplasmic localization, plus } \\
\text { optional C-terminal His.Tag } \\
\text { Vector for construction and expressing of chimeric protein containing Ipp'-ompA, Elongatus } \\
\text { and Chitin Binding domain }\end{array}$ & $\begin{array}{l}\text { Qiagen } \\
\text { Novagene } \\
\text { Constructed in this study } \\
\text { Constructed in this study }\end{array}$ \\
\hline \multicolumn{3}{|l|}{ Strain } \\
\hline BL21 DE3 & F-ompT gal dcm lon hsdSB (rB- mB-) $\lambda$ (DE3 [lacl lacUV5-T7 gene 1 ind1 sam7 nin5] & Stratagene \\
\hline $\begin{array}{l}\text { Top } 10 \\
\text { Staphylococcus aureus }\end{array}$ & $\begin{array}{l}\mathrm{F}^{\prime}[\text { laclq } T n 10 \text { (tetR)] mcrA } \Delta \text { (mrr-hsdRMS-mcrBC) } \varphi \text { 80lacZ } \triangle M 15 \triangle \text { lacX74 deoR nupG recA1 } \\
\text { araD139 } \Delta \text { (araleu) } 7697 \text { galU galK rpsL(StrR) endA1 } \lambda-\end{array}$ & Invitrogen \\
\hline
\end{tabular}


the expression of recombinant protein $\mathrm{n}$. In this study Human serum was used for binding analysis.

\section{Construction of plasmids, and protein expression}

The Lpp'-OmpA fragment was amplified by PCR using LPOA1 and LPOTA primers to construct pLOAa plasmid, previously made from the pET-LOA plasmid, containing a combining of the first nine $\mathrm{N}$-terminal amino acids of Lpp and amino acids 46 to 159 of OmpA were used as a template. The $381 \mathrm{bp}$ PCR product was digested with $N d e I-E c o R I$ restriction enzymes, followed by ligation into the previously digested pET26b vector.

PCR was carried out as per following conditions: Initial denature for $5 \mathrm{~min}$ at $94 \mathrm{C}$, amplify 30 cycles of $45 \mathrm{~s}$ at $94{ }^{\circ} \mathrm{C}$, annealing foe $45 \mathrm{~s}$ at $68^{\circ} \mathrm{C}$, extension for $60 \mathrm{~s}$ at $72{ }^{\circ} \mathrm{C}$, and final extension for $10 \mathrm{~min}$ at $72{ }^{\circ} \mathrm{C}$ on an MWG AG, Biotech, Primus 96 system (Germany). For gene cloning, the truncated $\mathrm{SpA}$ gene was amplified using primers PAF, PAR from $\sim 890 \mathrm{bp}$, S. aureus genome as a template $(100 \mathrm{ng} / 25 \mu \mathrm{l})$, and purified. To prepare the final construct of plasmid, SpA fragment (890 bp) and pLOAa were digested by EcoRI and XhoI and followed by ligation into the plasmid pLOAa. The vector was labeled as pLOA-PA pLOA-PA. Transformation of the vector into E. coli was carried out. It used $\mathrm{CaCl}_{2}$-mediated procedure. Overnight cultures of recombinant bacterial inoculated into $1 \mathrm{l}$ of fresh LB medium which contains $50 \mu \mathrm{g} / \mathrm{ml}$ kanamycin sulfate. To express fusion proteins, cultures were induced by using IPTG $0.1 \mathrm{mM}$, for $16 \mathrm{~h}$. Centrifugation was used at $10000 \mathrm{~g}$ for $2 \mathrm{~min}$ to harvest the cells.

\section{Preparation of surface-engineered E. coli displaying SpA protein}

A single colony of the recombinant $E$. coli harboring plasmids pLOA-PA was grown overnight in the LB media containing $35 \mu \mathrm{g} / \mathrm{ml}$ of kanamycin and was then inoculated into the fresh medium and continued for $8 \mathrm{~h}$ further incubation.

The bacterial culture was collected by centrifugation at $5000 \times g$ for $10 \mathrm{~min}$ followed by a washing step with $10 \mathrm{ml}$ PBS buffer by resuspended in PBS following a washing step. This was repeated for three more times.

The bacteria pellet was resuspended in $10 \mathrm{ml}$ of PBS $+0.02 \%$ sodium azide, transferred to a $250 \mathrm{ml}$ erlenmeyer flask and stirred at room temperature. Formaldehyde solution was added to give $1.5 \%$ final concentration and stirring was continued for $80 \mathrm{~min}$ at room temperature. Formaldehyde was removed by washing the suspension with $15 \mathrm{ml}$ of $1 \mathrm{X}$ PBS. After discarding the supernatant, the pellet was washed in PBS $+0.02 \%$ sodium azide as a $10 \%(\mathrm{w} / \mathrm{v})$ followed by a
5 min centrifugation at $5000 \times g$. After resuspension of the bacterial pellet in a $100 \mathrm{mM}$ Tris $-\mathrm{HCl}$ buffer $\mathrm{pH} 8$ containing $10 \%$ glycerol, it was stored at $4{ }^{\circ} \mathrm{C}$.

\section{IgG-binding assay}

The affinity and IgG-binding ability of the protein A-displaying $E$. coli was examined using IgG-binding assay with rabbit sera. The surface-engineered $E$. coli was washed with $1 \mathrm{~mL}$ of suspension buffer $(100 \mathrm{mM}$ Tris $-\mathrm{HCl} \mathrm{pH} \mathrm{8).} \mathrm{The} \mathrm{pH}$ of rabbit sera was increased to $7.5-8$ by $1 \mathrm{M}$ Tris of $\mathrm{pH} 8$ and it then added to the bacterial suspension followed by incubation for $1 \mathrm{~h}$ at $4{ }^{\circ} \mathrm{C}$. The surface-engineered bacteria were washed with $100 \mathrm{mM}$ Tris- $\mathrm{HCl}$ of $\mathrm{pH}$ 8. Elution buffer $(100 \mathrm{mM}$ glycine of $\mathrm{pH} 3$ containing $1 \mathrm{M} \mathrm{KCl}$ ) was used to release the bound IgGs from surface of the bacterial. Eluted fraction was dialyzed in $10 \mathrm{mM}$ Tris- $\mathrm{HCl}$ and then resolved on SDS-PAGE prepared according to Laemmli (1970) and then stained with Coomassie Brilliant Blue R-250. E. coli transformed with the parental plasmid $\mathrm{pLpp}^{\prime}$-OmpA without IgG-binding domain of SpA was used as a negative control.

\section{Results}

Complex binding of $\mathrm{SpA}$ with $\mathrm{IgG}_{\mathrm{Fc}}$

We evaluated the formation of the $\mathrm{pLpp}^{\prime}$-OmpA$\mathrm{SpA}_{295}-\mathrm{IgG}_{\mathrm{FC}}$ structure (Fig. 1) using a high-throughput computational approach. The root mean square deviation (RMSD) and the predicted structure of Lpp'OmpA-SpA 295 are presented in Fig. 2a. The RMSD shows the stability of the system after $30 \mathrm{~ns}$ of MD simulation. Binding site of the correct structure obtained from molecular dynamic to $\operatorname{IgG}_{\mathrm{FC}}$ determined by docking. The docking cluster scoring models are according to the energy range from the minimum energy interaction of protein-protein complexes. We selected the complex with the lowest free energy from docking to for following molecular dynamic simulation for $30 \mathrm{~ns}$ that the resulted structure is in Fig. $2 b$.

The H-bonds among $\mathrm{SpA}_{295}$ with $\mathrm{IgG}_{\mathrm{Fc}}$ were displayed in Fig. 3. Pro59, Asp99, Asn142, Ala44, Ala63, Gln64, Asn67, Glu9 in SPA involved in $\mathrm{H}$ - bond with IgG. van der Waals and ionic bonding between IgGFc and SpA295 are also seen in the Fig. 3. Glu9, Asp99, Glu145 make ionic bond with IgG.

Hydrophobic sites on the surface of SpA in the region that interact with IgG (Fig. 4a) and the surface electrostatic potential of SpA are observed in Fig. 4b. As can be seen, the number of hydrophilic amino acids and also, negatively charged amino acids are more common in the interaction site. 


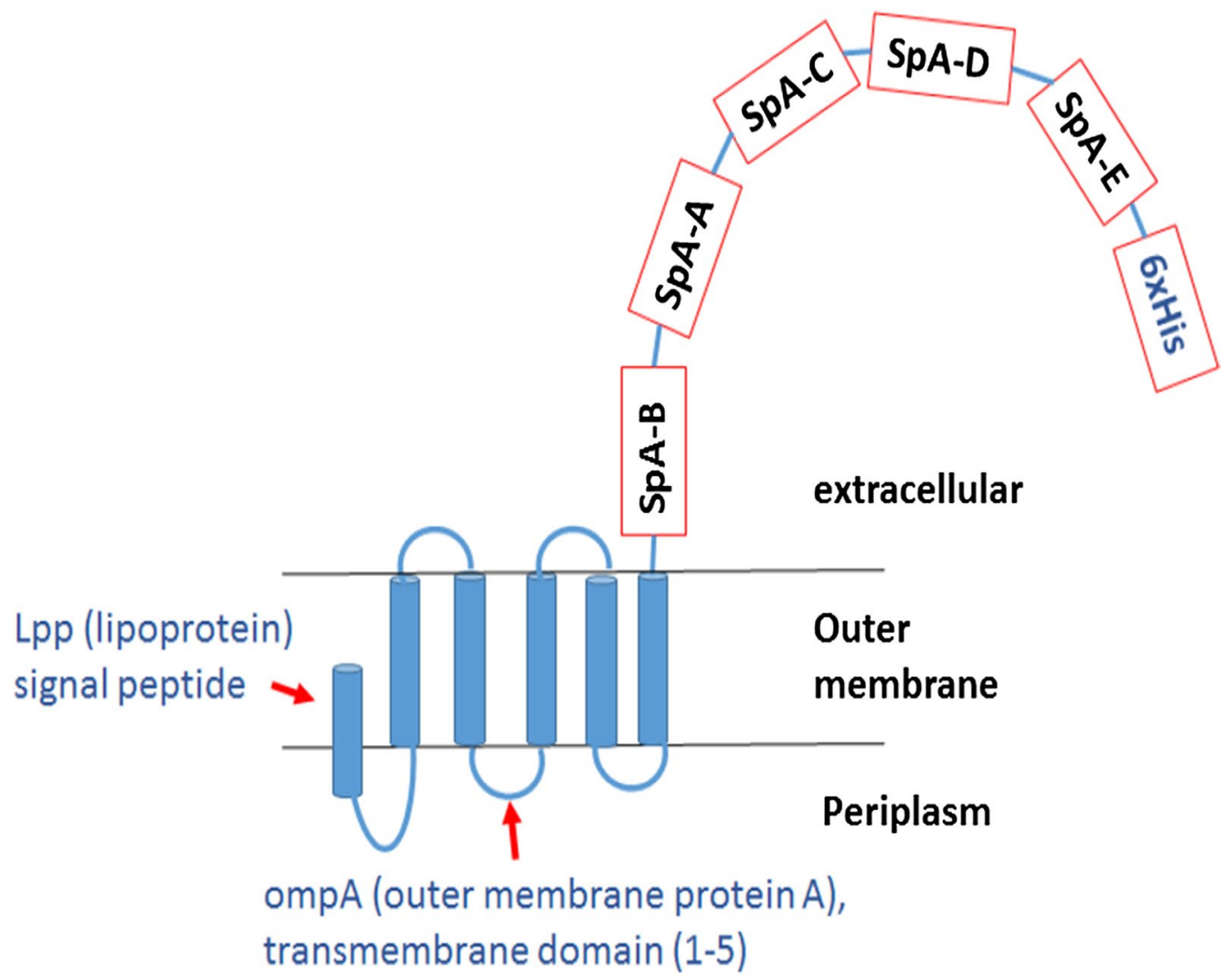

Fig. 1 Schematic illustration of Lpp'-OmpA, SpA 295 complex

\section{Plasmid construction and protein expression}

Surface attachment of the protein A (SpA) containing E, D, A, B and C domains (Additional file 1: Figure S1) on the surface of E. coli BL21 (DE3) was successfully done using the Lpp'-OmpA system. The construct of Lpp'-ompA-Spa in pET26b plasmid was made. DNA sequence of $\mathrm{pLpp}^{\prime}$-ompA-Spa construct cloned in $\mathrm{pET} 26 \mathrm{~b}$, and protein sequence of $\mathrm{p} \mathrm{Lpp}{ }^{\prime}$-ompA-Spa construct are provided in Additional file 1: Figure S2.

Construction of the pET26b plasmid was verified by restriction enzyme digestions (Additional file 1: Figures S3-S5), and DNA sequencing. Amplification of protein A performed using PCR reactions at different temperatures (Additional file 1: Figure S6). Detection of non-recombinant and recombinant plasmids pET26 was performed by enzymatic digestion (Additional file 1: Figure S7) and electrophoretic mobility shift assay (Additional file 1: Figure S8).

The expression of the fusion truncated $\mathrm{SpA}$ and the control protein was carried out using E. coli BL21 DE3 and IPTG as an inducer. The protein expression by $E$. coli transformed with recombinant plasmids pET-LOA (Fig. 5, line 1-3) and pLOA-PA (Fig. 5, line 4-5) was evaluated using SDS-PAGE analysis (Additional file 1: Figures S9 and S10).

The recombinant truncated Protein A contains five Ig-binding regions of protein A and a $6 \times$ His-tag at the C-terminus. To prevent nonspecific binding to IgG, the albumin binding region and other regions present in $\mathrm{SpA}$ was removed to ensure specific IgG binding. Immobilized metal affinity chromatography (IMAC) was used to purify the recombinant $\mathrm{C}$-terminus $6 \mathrm{X}$ his-tag fusion of the SpA. Meanwhile, using anti-His-tag antibody the fusion protein A can be detected. The recombinant Protein $\mathrm{A}$ is ideal for immunoprecipitation and purification of antibodies as it is able to binds to most human and mouse IgG subclasses of human and mouse.

\section{Binding assay for SpA-displayed recombinant E. coli}

The recombinant SpA-displaying E. coli adsorbent that developed in this work was used for purification of the IgG from rabbit serum. After binding and two steps of washing to remove nonspecific proteins, the protein A eluted from the bioabsorbent contained mainly IgG molecules. 


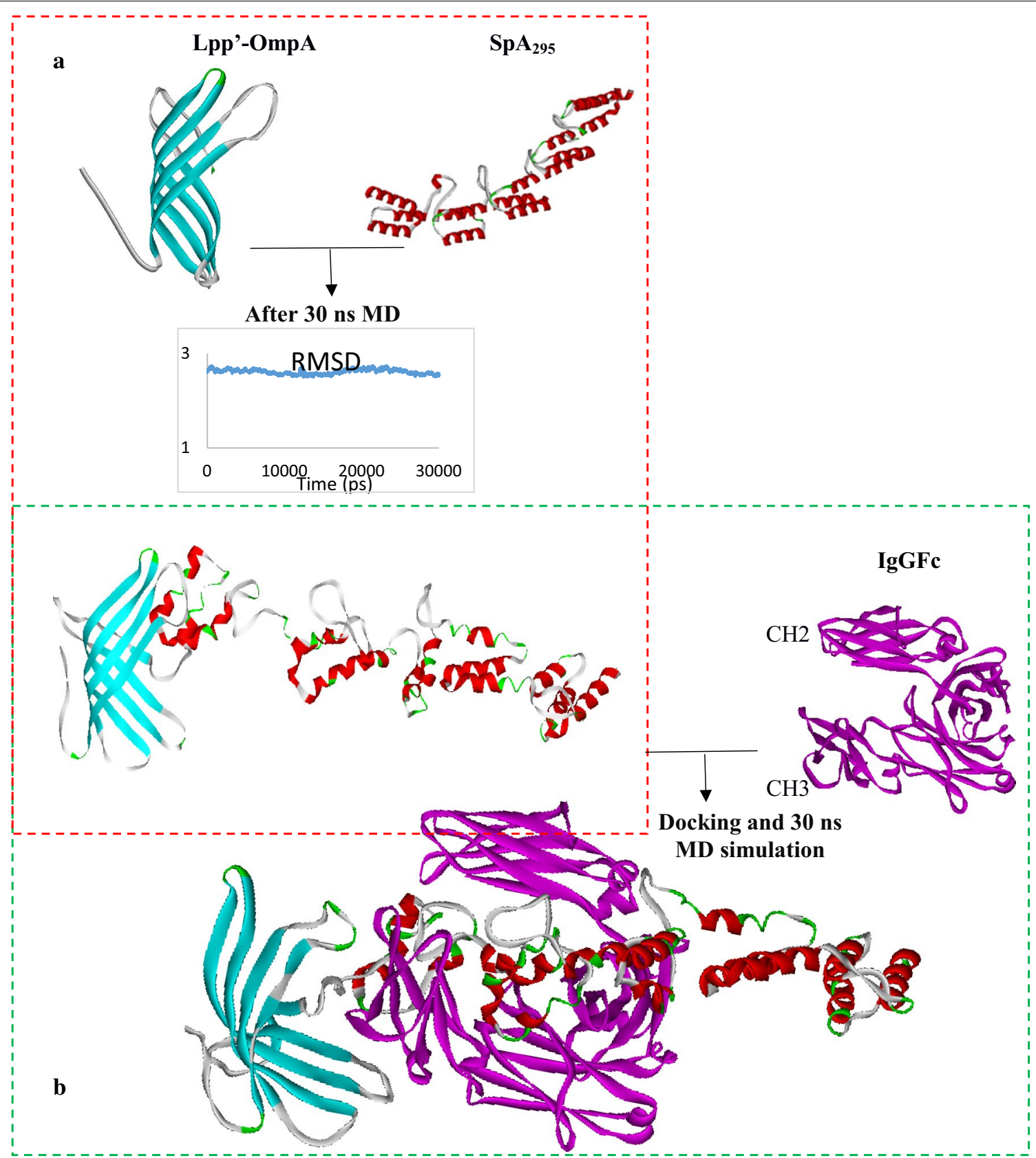

Fig. 2 a The primary structure of $\mathrm{Lpp}^{\prime}-\mathrm{OmpA}, \mathrm{SpA}_{295}$ and its complex after $30 \mathrm{~ns}$ molecular dynamics, RMSD plot of protein structure compared to the primary structure. $\mathbf{b} \mathrm{Lpp}^{\prime}-\mathrm{OmpA}-\mathrm{Spa}_{295}$ and $\mathrm{lgG}_{\mathrm{FC}}$ and their cpmlex after docking and $30 \mathrm{~ns}$ molecular dynamics simulation

The presence of the protein bands corresponding to the IgG heavy and light chains (about $50 \mathrm{kDa}$ and $>25 \mathrm{kDa}$, respectively) on polyacrylamide gel further verifies that IgG has adhered to the protein A immobilized on the recombinant $E$. coli surface (Fig. 5 line 6 and 7). The results of the IgG purification were also comparable with that of the one achieved by commercial protein A- agarose in which the SpA is immobilized on the surface of this polymer. Eluted IgG from protein A-agarose support prepared in this study was qualitatively comparable to purified IgG using immobilized protein A agarose matrix supports by SDS-PAGE analysis as shown in Fig. 5 line 8. It is notable that protein $\mathrm{A}$ bind and extracts the intact form of IgG from serum by attaching to its Fc region, without changing the conformation and structure of IgG as it occurs when a reducing agent such as DTT which 


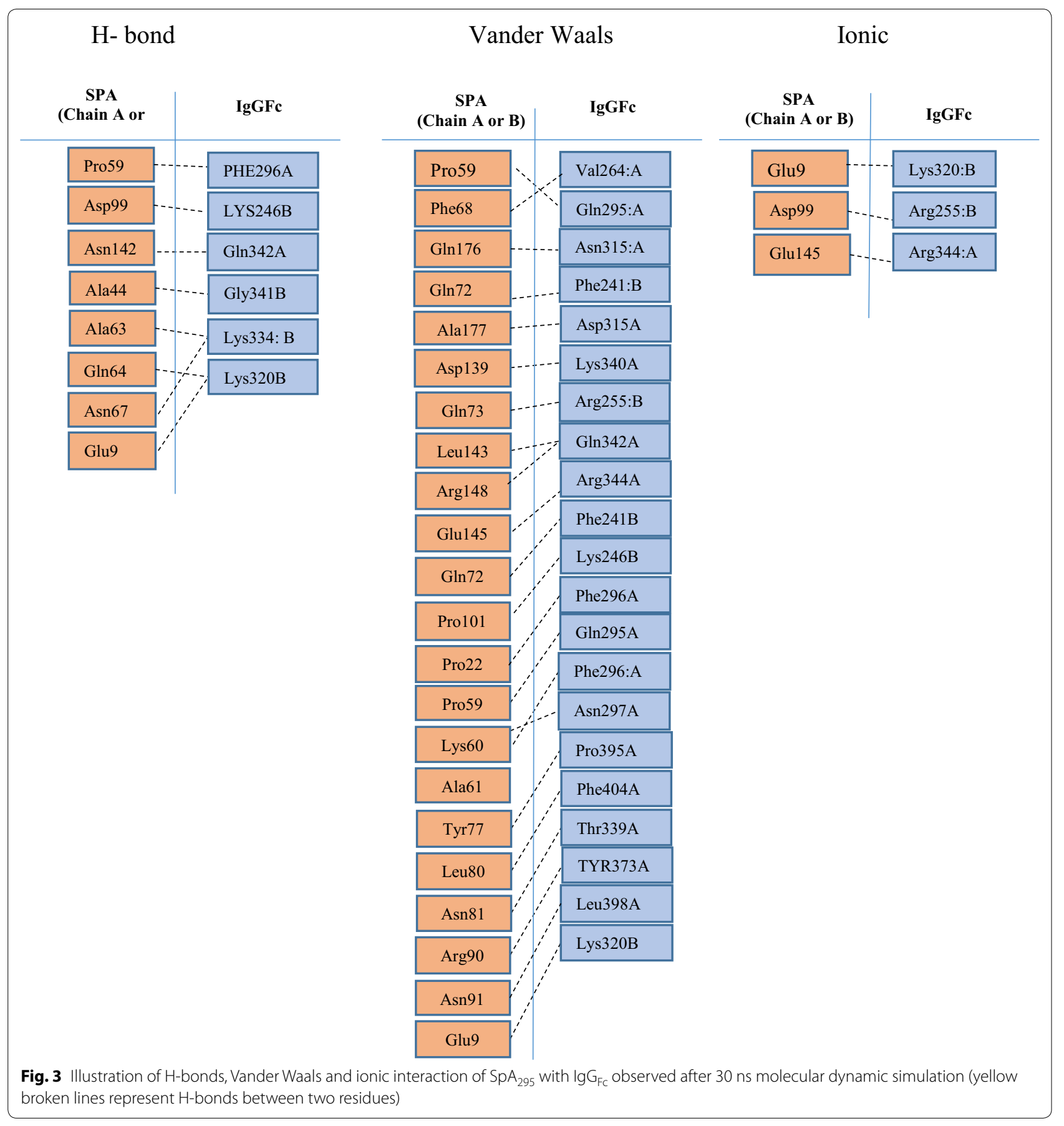

breaks $\mathrm{S}-\mathrm{S}$ bond is present in the buffers and cause dissociation of heavy chain and light chain of IgG.

\section{Discussion}

Antibody purification using Protein A (SpA), immobilized to different solid surfaces, is commonly used in research laboratories or commercial antibody manufacturing. Increasing the stability of SpA protein under harsh treatment/washing conditions is an important factor to increase the yield and quality of purified antibodies (Rigi et al. 2019; Cherf and Cochran 2015). One of the major strategies to increase proteins stability is display of proteins on the surface of a live cell as an alternative to classic protein immobilization approach (Lozančić et al. 2019; Grewal, et al. 2016). 

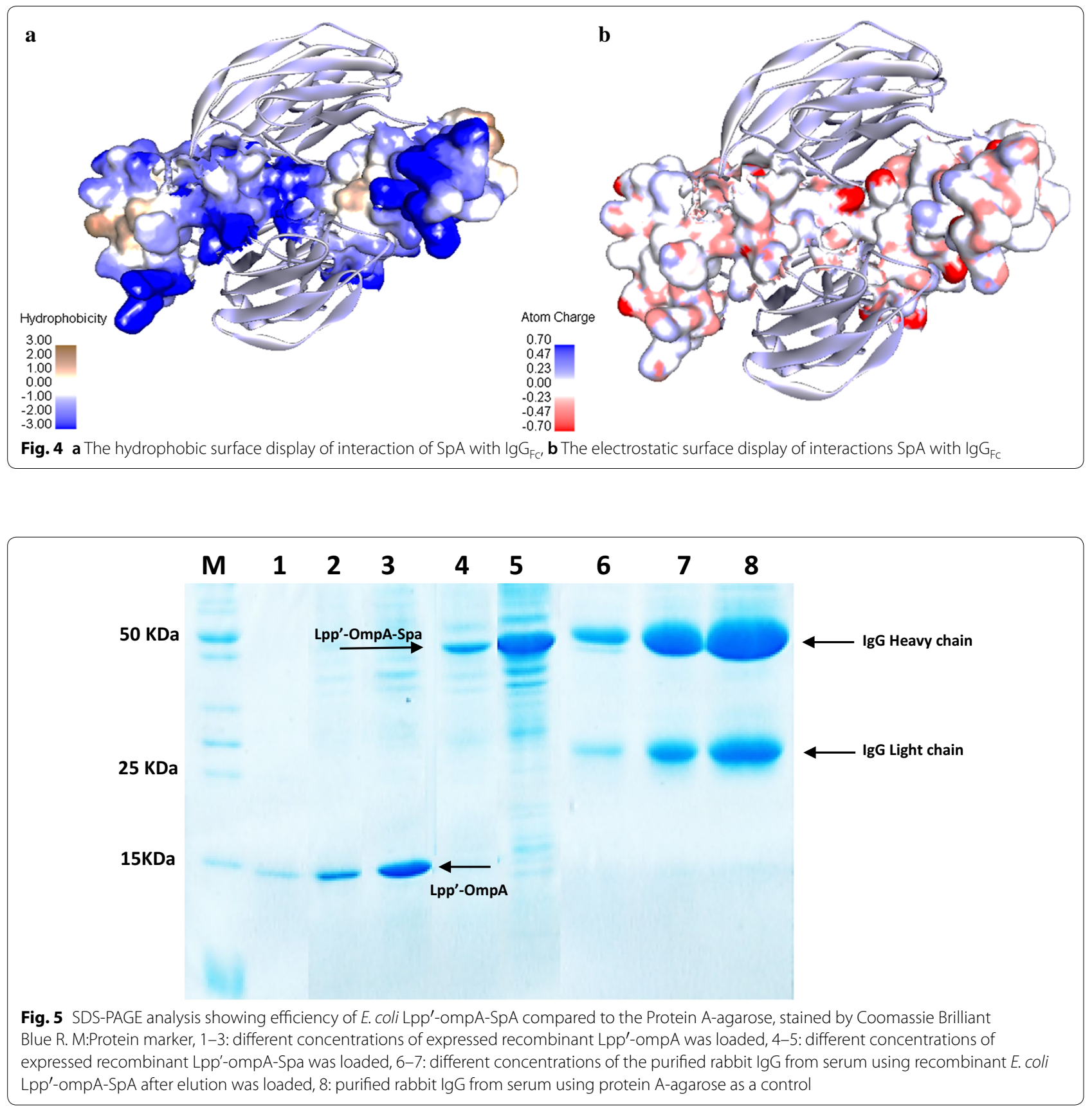

The classical immobilization of recombinant proteins on the surface of a matrix (Khodaei et al. 2018) is sometimes challenging because the protein may lose its conformation and consequently its function. However, anchoring proteins is a mild approach to immobilize heterologous proteins to outer membranes of the cell. In this way, the host cell produces the heterologous protein while covalently attaching it to its surface. In this worke, we used the $E$. coli surface display method to express SPA protein for IgG isolation. The immunoadsorbent generated from $E$. coli surface display, in addition to the other benefits mentioned, can be quickly generated in a cost-effective way and stored lyophilized at room temperature, which will be stable for several months and reduces the cost of downstream processes in industry as well.

The efficiency of surface display systems and the correct and efficient protein folding and its stability is highly related to the specifications of the carrier protein, passenger protein, and fusion method (Yang. et al. 
2008a, b; Barrett et al. 2019). LPP-ompA is an efficient surface display system that has been developed and applied for various applications (Fasehee et al. 2018; Rigi et al. 2014; Tafakori et al. 2012). In this research project using Lpp'-OmpA as an SPA anchor, in the initial design we performed physico-chemical and structural studies on chimeric protein using molecular dynamics tools to ensure the strength and stability of this new structure on the cell surface.

Computational analysis showed that the surface expression of $\mathrm{SpA}_{295}$ creates a stable structure and does not form undesirable bonds with the Lpp'-OmpA surface protein, and maintains its binding structure to $\mathrm{IgG}_{\mathrm{Fc}}$. Furthermore, the analysis displayed in the binding of Lpp'-OmpA-SpA297 complex to $\operatorname{IgG}_{\mathrm{F}} \mathrm{C}$ in which aminoacids involve in Vander Waals interaction, hydrogen binding and ionic binding.

In the experimental work, surface expression of this new the recombinant protein system by five replicate domains of protein A on the surface of Escherichia coli BL21 and the power of IgG separation confirmed computer simulation findings. The absorption rate under the five SpA repeatitive domain systems was extremely high. Higher IgG-binding yield is demonstrated by SDS-PAGE analysis which can be used as a suitable alternative to conventional immune precipitates.

The surface display system used in this study seems to be suitable for surface engineering of $E$. coli to immobilize various ligands and proteins in their active state. An advantage of the current system over conventional commercially available immobilization matrix is simplicity, high production rate, easier production and handling processes, and the lower cost of preparing the.

The matrix created in this work is able to separate IgG from human sera as a functional assay and considering the yield, purity of IgG and the cost of producing the matrix, this system can be used to develop an efficient immunoadsorbent.

We have shown that the displayed protein domains with specific functions of IgG purification at the cellular surface are accessible in binding studies. Furthermore, with the whole cell as a matrix, the proteins have proven to be more stable, therefore making downstream processes of associated preparations and protein purification redundant. Further investigation on this system is required to achieve higher production rates and specificity at the industrial scale.

\section{Supplementary information}

Supplementary information accompanies this paper at https://doi. org/10.1186/s13568-020-01097-1.
Additional file 1: Figure S1. Schematic diagram Of Protein A domains. Figure S2. A) DNA Sequence of $p$ Lpp'-ompA-Spa construct cloned in $p E T 26 b$, and B) protein sequence of $p$ Lpp'-ompA-Spa construct. Figure S3. Schematic diagram showing the strategy for making recombinant plasmid pLpp'-ompA-Spa. Figure S4. Investigation of electrophoretic mobility shift assay of different recombinant clones on $1 \%$ agarose gel to confirm cloning using quick check extraction method. Figure S5. Investigation of enzymatic cleavage of recombinant pLpp'-ompA plasmids with Ndel and EcoRl restriction enzymes by $1 \%$ agarose gel electrophoresis.

Figure S6. Amplification of protein A using PCR reactions at different temperatures from 54 to 57 from left to right. Figure S7. Enzymatic digestion of non-recombinant and recombinant plasmids pET26. Figure S8. Investigation of electrophoretic mobility shift assay of different recombinant clones on $1 \%$ agarose gel to confirm cloning using quick check extraction method. Figure S9. Relative expression and purification of $L p p^{\prime}-o m p A$ and Lpp'-ompA-Spa in E. coli (BL21-DE3) under control of the T7 promoter. Figure S10. Expression of Lpp'-ompA-Spa construct in E. coli (BL21-DE3).

\section{Abbreviations}

SpA: Staphylococcus aureus protein A; IgG: Immunoglobulin G; ompA: Outer membrane protein $A$; Lpp'-ompA: Truncated outer membrane protein $A$; IPTG: Isopropylthiogalactopyranoside; IgBDs: Ig-binding domains; LB medium: Luria-Bertani medium.

\section{Acknowledgements}

This research was supported by the National Institute of Genetic Engineering and Biotechnology, Tehran, Iran.

\section{Authors' contributions}

FR performed computational simulation. MV conducted most of the experiments. VT is contributed to this work by doing some experiments and data analysis. AN collected the bioinformatics data and helped as a technical assistant. GA (corresponding author) designed the experiments, supported the project, analyzed data and wrote the final manuscript t. All authors read and approved the final manuscript.

Funding

Not applicable.

Availability of data and materials

Not applicable.

Ethics approval and consent to participate

Not applicable.

Consent for publication

Not applicable.

\section{Competing interests}

The authors declare that they have no competing interests.

\section{Author details \\ ${ }^{1}$ Department of Toxico/Pharmacology, School of Pharmacy, Shahid Beheshti University of Medical Sciences, Niayesh Highway, Valiasr Ave, Tehran 6153-14155, Iran. ${ }^{2}$ Pharmaceutical Sciences Research Center, Shahid Beheshti University of Medical Sciences, Niayesh Highway, Valiasr Ave, Teh- ran 14155-1817, Iran. ${ }^{3}$ Physiology Research Center, Faculty of Medicine, Iran University of Medical Sciences, Tehran, Iran. ${ }^{4}$ Department of Cell \& Molecular Sciences, Faculty of Biological Sciences, Kharazmi University, Tehran, Iran. ${ }^{5} \mathrm{PhD}$ Student in Fisheries Products Processing Group, Faculty of Fisheries and Envi- ronmental Sciences, Gorgan University of Agricultural Sciences and Natural Resources, Gorgan, Iran. ${ }^{6}$ Department of Environmental and Industrial Biotechnology, National Institute of Genetic Engineering and Biotechnol- ogy (NIGEB), P.O.BOX: 14965/161, Tehran 1497716316, Iran. ${ }^{7}$ Present Address: Department of Cell and Molecular Biology, Uppsala University, P.O. Box 256, 75105 Uppsala, Sweden.}

Received: 11 July 2020 Accepted: 26 August 2020 Published online: 03 September 2020 


\section{References}

Barrett CT, Webb SR, Dutch RE (2019) A hydrophobic target: using the paramyxovirus fusion protein transmembrane domain to modulate fusion protein stability. J Virol 93(17):e00863-19

Boyle MDP (1990) In bacterial immunoglobulin-binding proteins. In: Boyle M (ed) Applications in immunotechnology, vol 2. Academic Press Inc, San Diego, pp 3-13

Cary S, Krishnan M, Marion TN, Silverman GJ (1999) The murine clan V(H) III related 7183, J606 and S107 and DNA4 families commonly encode for binding to a bacterial B cell superantigen. Mol Immunol 36:769-776

Cavallari M (2017) Rapid and direct VHH and target identification by staphylococcal surface display libraries. Int J Mol Sci 18:1507-1524

Cherf GM, Cochran JR (2015) Applications of yeast surface display for protein engineering. In: Liu B (ed) Yeast surface display. Methods in molecular biology, vol 1319. Humana Press, New York

Fasehee H, Rostami A, Ramezani F, Ahmadian G (2018) Engineering E. coli cell surface in order to develop a one-step purification method for recombinant proteins. AMB Expr 1:107

Francisco JA, Earhart CF, Georgiou G (1992) Transport and anchoring of betalactamase to the external surface of Escherichia coli. Proc Natl Acad Sci USA 89:2713-2717

Furst AL, Hoepker AC, Francis MB (2017) Quantifying hormone disruptors with an engineered bacterial biosensor. ACS Cent Sci 3:110-116

Georgiou G, StephensD L, Stathopoulos C, Poetschke HL, Mendenhall J, Earhart CF (1996) Display of $\beta$-lactamase on the Escherichia coli surface: outer membrane phenotypes conferred by Lpp'-OmpA'- $\beta$-lactamase fusions. Protein Eng 9:239-247

Ghahremanifard P, Rezaeinezhad N, Rigi G, Ramezani F, Ahmadian G (2018) Designing a novel signal sequence for efficient secretion of candida antarctica lipase B in E. coli: the molecular dynamic simulation, codon optimization and statistical analysis approach. Int J Biol Macromol 119:291-305

Grewal YS, Shiddiky MJA, Mahler SM, Cangelosi GA, Trau M (2016) Nanoyeast and other cell envelope compositions for protein studies and biosensor applications. ACS Appl Mater Interfaces 8(45):30649-30664

Hadji-Ghasemi F, Gharagozlou S, Ghods R, Roohi A, Khoshnoodi J, Shokri F (2003) Generation and characterization of a mouse monoclonal antibody with specificity similar to staphylococcal protein A (SPA). Hybrid Hybridomics 22:33-39

Hashemzadeh S, Ramezani F, Rafii-Tabar H (2018) Study of molecular mechanism of the interaction between MEK1/2 and trametinib with docking and molecular dynamic simulation. Interdiscip Sci 1:115-124

Kalyanasundram J, Chia SL, Song AA, Raha AR, Young HA, Yusoff K (2015) Surface display of glycosylated Tyrosinase related protein-2 (TRP-2) tumour antigen on Lactococcus lactis. BMC Biotechnol 15:113-123

Khodaei S, Ghaedmohammadi S, Mohammadi M, Rigi G, Ghahremanifard P Zadmard R, Ahmadian G (2018) Covalent immobilization of protein A on chitosan and aldehyde double-branched chitosan as biocompatible carriers for immunoglobulin G (IGg) Purification. J Chromatogr Sci 56(10):933-940

Kim HK, Cheng AG, Kim HY, Missiakas DM, Schneewind O (2010) Nontoxigenic protein A vaccine for methicillin-resistant Staphylococcus aureus infections. J Exp Med 207:1863-1870
Laemmli UK (1970) Cleavage of structural proteins during the assembly of the head of bacteriophage T4. Nature 227:680-685

Lofdahl S, Guss B, Uhlen M, Philipson L, Lindberg M (1983) Gene for staphylococcal protein A. Proc Natl Acad Sci USA 80:697-701

Lozančić M, Sh Hossain A, Mrša V, Teparić R (2019) Surface display-an alternative to classic enzyme immobilization. Catalysts 9(9):728

Pieper U, Webb B, Dong G, Schneidman-Duhovny D, Fan H, Kim SJ, Khuri N, Spill YG, Weinkam P, Hammel M, Tainer JA, Nilges M, Sali A (2014) ModBase, a database of annotated comparative protein structure models and associated resources. Nucleic Acids Res 42:336-346

Rigi G, Mohammadi SG, Arjomand MR, Ahmadian G, Noghabi KA (2014) Optimization of extracellular truncated staphylococcal protein A expression in Escherichia coli BL 21 (DE 3). Biotechnol appl biochem 61(2):217-225

Rigi G, Ghaedmohammadi S, Ahmadian G (2019) A comprehensive review on staphylococcal protein $A(S p A)$ : its production and applications. Biotechnol Appl Biochem 66(3):454-464

Sjodahl J (1977) Repetitive sequences in protein A from Staphylococcus aureus Arrangement of five regions within the protein, four being highly homologous and Fc-binding. Eur J Biochem 73:343-351

Tafakori V, Ahmadian G, Amoozegar MA (2012) Surface display of bacterial metallothioneins and a chitin binding domain on Escherichia coli increase cadmium adsorption and cell immobilization. Appl Biochem Biotechnol 167:462-473

Tafakori V, Zadmard R, Tabandeh F, Amoozegar MA, Ahmadian G (2014) Equilibrium isotherm, kinetic modeling, optimization, and characterization studies of cadmium adsorption by surface-engineered Escherichia coli. Iran Biomed J 21:380-391

Tashiro M, Montelione GT (1995) Structures of bacterial immunoglobulinbinding domains and their complexes with immunoglobulins. Curr Opin Struct Biol 5:471-481

Ton-That H, Liu G, Mazmanian SK, Faull KF, Schneewind O (1999) Purification and characterization of sortase, the trans peptidase that cleaves surface proteins of Staphylococcus aureus at the LPXTG motif. Proc Natl Acad Sci USA 96:12424-12429

Van Der Spoe D, Lindahl E, Hess B, Groenhof G, Mark AE, Berendsen HJ (2005) GROMACS: fast, flexible, and free J Comput Chem 16:1701-1718

Yan Y, Zhang D, Zhou P, Li B, Huang SY (2017) HDOCK: a web server for proteinprotein and protein-DNA/RNA docking based on a hybrid strategy. Nucleic Acids Res 45:365-373

Yang C, Zhu Y, Yang J, Liu Z, Qiao C, Mulchandani A, Oiao C, Mulchandani A Chen W (2008a) Development of an autofluorescent whole-cell biocatalyst by displaying dual functional moieties on Escherichia coli cell surfaces and construction of a coculture with organophosphate-mineralizing activity. Appl Environ Microbiol 74:7733-7739

Yang Z, Liu Q, Wang Q, Zhang Y (2008b) Novel bacterial surface display systems based on outer membrane anchoring elements from the marine bacterium Vibrio anguillarum. App Environ Microbiol 74(14):4359-4365

\section{Publisher's Note}

Springer Nature remains neutral with regard to jurisdictional claims in published maps and institutional affiliations.

\section{Submit your manuscript to a SpringerOpen ${ }^{\circ}$ journal and benefit from:}

- Convenient online submission

- Rigorous peer review

- Open access: articles freely available online

- High visibility within the field

Retaining the copyright to your article

Submit your next manuscript at springeropen.com 